\title{
DIFFERENCE OF EVAPORATION AND BOILING FOR HETEROGENEOUS WATER DROPLETS IN A HIGH- TEMPERATURE GAS
}

\author{
Jean Claude Legros ${ }^{1,2}$, Maxim V. Piskunov ${ }^{1,}$, , Pavel A. Strizhak ${ }^{1}$ \\ ${ }^{1}$ National Research Tomsk Polytechnic University, 634050 Tomsk, Russia \\ ${ }^{2}$ Université Libre de Bruxelles, 1050 Brussels, Belgium
}

\begin{abstract}
Experimental investigation of vapor formation was carried out on water droplets on fixed graphite substrate and heterogeneous droplets (containing solid single inclusions) when heating in high-temperature gas. High-speed video shooting (up to $10^{5}$ frames per second), optical method (Particle Image Velocimetry) and TEMA Automotive software were used. We revealed two phase change mechanisms of heterogeneous liquid droplets. Effect of evaporation and boiling on evaporation times of water droplets was determined.
\end{abstract}

\section{Introduction}

Results of the research [1,2] show the practical significance of the solid inclusions insert into water droplets. Besides, the significant intensification of phase changes on inside interfaces is achieved. The increase of water application efficiency in such branches of industry and national economy as thermal engineering, chemical and petrochemical industry, fire safety is the prospective line of development.

There is the complicated and poorly studied problem of determination of the main mechanism of phase changes when heating heterogeneous water droplets (with solid inclusions) in a hightemperature gas (about $1100 \mathrm{~K}$ ) and conditions for different phase changes. A solution of such problem will allow to use the considered approach of phase change intensification to improve current multiphase high-temperature technologies (for instance, [3]).

The purpose of the present work is to investigate the characteristics of vapor formation of water in a high-temperature gas on a substrate and in a heterogeneous droplet.

\section{Experimental setup and procedure}

Experimental research was performed in the setup, which is similar to the one used in [2]. This setup has the following main components: high-speed video cameras (up to $10^{5}$ frames per second) to reveal features and characteristics of the processes considered, a cross-correlation digital camera and a double pulse solid-state laser to use optical method (Particle Image Velocimetry (PIV). The measurement of heterogeneous liquid droplet sizes was carried out by using TEMA Automotive software.

\footnotetext{
${ }^{a}$ Corresponding author: piskunovmv@tpu.ru
} 
The experiment procedure included several stages (Fig. 1).
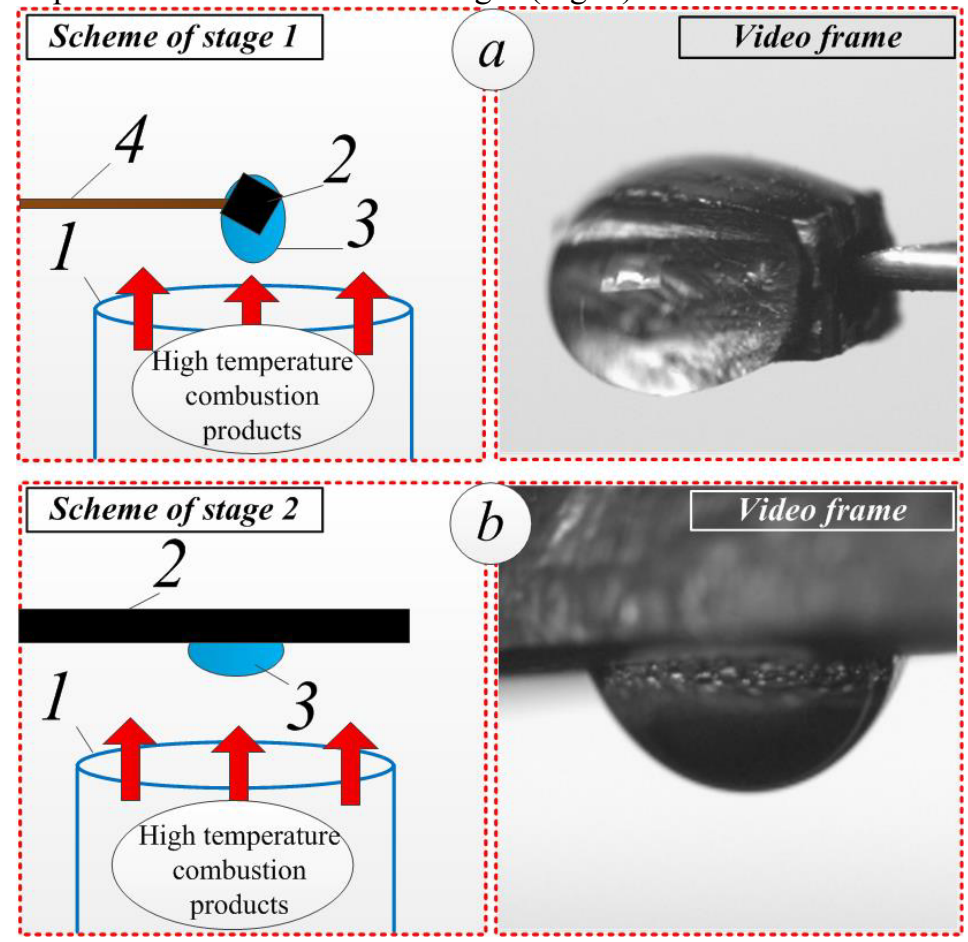

Figure 1. Scheme of research stages and video frames of these stages $(a-$ heterogeneous droplet fixed on the ceramic rod; $b$ - water droplet on the graphite substrate): 1 - cylinder of quartz glass, 2 - graphite substrate / solid (graphite) inclusion, 3 - water droplet, 4 - ceramic rod

The preparation step was to manufacture the graphite substrate with required sizes (length $-0.1 \mathrm{~m}$, thickness $-0.005 \mathrm{~m}$, width $-0.01 \mathrm{~m})$ and graphite inclusions 2 with different sizes $(2,3$ and $4 \mathrm{~mm})$. Water droplets 3 of required mass were generated by using the dosing device. High-temperature combustion products have filled the cylindrical channel 1 after igniting of industrial ethanol in burner on the bottom of the cylinder 1 . PIV method was used to control the flow velocity of industrial ethanol combustion products $u_{\mathrm{g}}$.

On the first stage of research we studied the vapor formation conditions, at which a heterogeneous droplet was fixed on the ceramic rod 4 and heated at high temperature (Fig. 1, a). The movement of the ceramic rod 4 with heterogeneous droplet was performed by automated moving elements. We carried out the recording of life times (time of complete evaporation) of heterogeneous droplets $\tau_{\mathrm{h}}$. Also, a change in heterogeneous droplets sizes was controlled by TEMA Automotive software.

On the second stage of research (Fig. 1,b) the ceramic rod 4 was changed to the graphite substrate 2. The water droplet 3 was lowered on the substrate surface 2 . Such water droplet/substrate system was turned over and moved to the top of cylinder 1 .

We carried out at least 10 tests at each stage under identical conditions (initial diameters of droplets $d_{0}$, liquid temperatures $T_{\mathrm{w}}$, gas temperatures $T_{\mathrm{g}}$ and flow velocities of gas $u_{\mathrm{g}}$ ).

Errors in size measurements of inclusion and water droplet did not exceed $0.05 \mathrm{~mm}$. Repeatability of $d_{0}$ determination was $7 \%$. Errors on life times determination were $0.005 \mathrm{~s}$.

\section{Results and discussion}

Tab. 1 reports results of life times for water droplets on the graphite substrate and droplets with solid inclusions of different sizes when increasing a temperature of combustion products. Concerning heterogeneous water droplets, it may be concluded that the time of complete evaporation $\tau_{\mathrm{h}}$ is 
significantly decreased by increasing surface area of an inclusion. By increasing contact area of an inclusion and a liquid layer, the heat energy stored by inclusion is intensively transferred to the water layer. Therefore, the water layer is evaporated faster. For the water droplet evaporating from the substrate, the life time is changed insignificantly (up to $5 \mathrm{~s}$ ) when increasing water mass from 5 to 15 mg. Large life times of droplets (close to times for heterogeneous droplets) and their insignificant change when increasing water mass are due to the heat insulating vapor film formation [4] between the graphite substrate and water droplet. This film slows down evaporation.

Table 1. Life times (complete evaporation time) of water droplets on the substrate and when full coating the inclusions with different sizes at temperature rise of combustion products

\begin{tabular}{|c|c|c|c|c|c|c|c|c|c|c|c|}
\hline \multirow{4}{*}{$\begin{array}{c}2 \mathrm{~mm} \\
\text { inclusion }\end{array}$} & $\begin{array}{l}\mathrm{m}_{\mathrm{w}}, \\
\mathrm{mg}\end{array}$ & $\tau_{\mathrm{h}}, \mathrm{s}$ & \multirow{4}{*}{$\begin{array}{c}3 \mathrm{~mm} \\
\text { inclusion }\end{array}$} & $\begin{array}{l}\mathrm{m}_{\mathrm{w}}, \\
\mathrm{mg}\end{array}$ & $\tau_{\mathrm{h}}, \mathrm{s}$ & \multirow{4}{*}{$\begin{array}{c}4 \mathrm{~mm} \\
\text { inclusion }\end{array}$} & $\begin{array}{l}\mathrm{m}_{\mathrm{w}}, \\
\mathrm{mg}\end{array}$ & & \multirow{4}{*}{$\begin{array}{l}\text { Subs } \\
\text { trate }\end{array}$} & $\begin{array}{l}\mathrm{m}_{\mathrm{w}}, \\
\mathrm{mg}\end{array}$ & $\tau_{\mathrm{h}}, \mathrm{s}$ \\
\hline & 5 & 26.80 & & 5 & 14.17 & & 5 & 13 & & 5 & 20.34 \\
\hline & 10 & 34.88 & & 10 & 28.38 & & 10 & 25.60 & & 10 & 22.11 \\
\hline & 15 & 42.21 & & 15 & 36.25 & & 15 & 29.70 & & 15 & 27.18 \\
\hline
\end{tabular}

Fig. 2 reports results of differences of complete evaporation times of water (with identical initial mass) on the substrate and around inclusion at different gas temperatures. The gas temperature was in the range from $400 \mathrm{~K}$ to $650 \mathrm{~K}$ (similar to procedure [5]). Note that the divergence of $\Delta \tau_{\mathrm{h}}$ parameter can be $20 \mathrm{~s}$ at low temperatures. The decrease of $\Delta \tau_{\mathrm{h}}$ parameter divergence (up to $3 \mathrm{~s}$ at $T_{\mathrm{g}}=650 \mathrm{~K}$ ) is observed at temperature rise. So, the vapor formation processes for systems under investigation can be due to close $\tau_{\mathrm{h}}$ at high temperatures of gas. It should be noted that there are some differences of these processes (first of all, concerning the mechanisms of vapor formation at liquid / solid interfaces). It was established that the main mechanism of phase changes during water droplet evaporation on the substrate is the vapor formation at water / graphite substrate interface. For the fixed heterogeneous droplet, the two phase change mechanisms are characteristic (evaporation from outside (free) surface and vapor formation at water / solid interface). The liquid evaporation from outside surface of heterogeneous droplet was followed by decrease of droplet sizes (such phenomenon was not observed while heating the water droplet on the substrate). The vapor film formation at interfaces was characteristic during both cases considered.

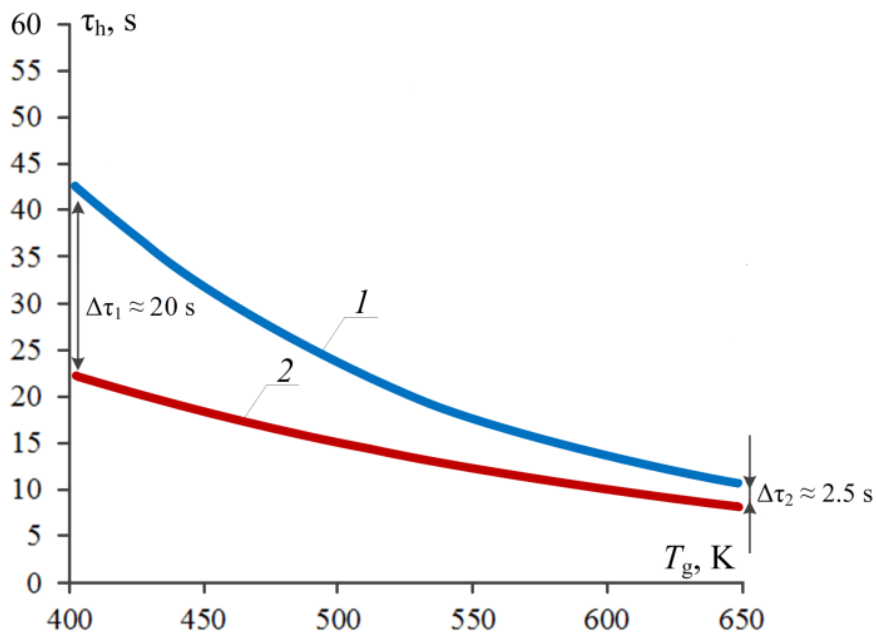

Figure 2. Life times of water droplet (mass is $10 \mathrm{mg}$ ) when coating the inclusion (1) and on the substrate (2) at gas temperature rise from $400 \mathrm{~K}$ to $650 \mathrm{~K}$ 


\section{MATEC Web of Conferences}

The analysis of research results allow to conclude that the implementation of one or several phase change mechanisms has a significant effect on evaporation time of liquid. We can recommend the variation of inclusion sizes to get the required life times of heterogeneous droplets. It is appropriate to investigate in detail the processes of vapor bubble formation, their growth and coalescence at liquid / solid interface and to develop approaches for intensification of these processes in heterogeneous droplets.

\section{Conclusion}

The implementation of the two phase change mechanisms of heterogeneous liquid droplets and their impact on liquid evaporation times $\tau_{\mathrm{h}}$ were established. We showed the impact of vapor film formation on life times of droplet evaporating from the substrate (insignificant change (to $20 \%$ ) of $\tau_{\mathrm{h}}$ when increasing the initial mass from 5 to $15 \mathrm{mg}$ ). The differences of complete evaporation times of water on the substrate and around inclusion were determined at different temperatures of heating (the divergence of $\Delta \tau_{\mathrm{h}}$ parameter was about $3 \mathrm{~s}$ at high temperatures of gas).

This work was supported by the grant of the President of the Russian Federation (MD-2806.2015.8).

\section{References}

1. R.S. Volkov, M.V. Piskunov, G.V. Kuznetsov, P.A. Strizhak, J. Heat Transfer 138, 1 (2016).

2. I.S. Anufriev, G.V. Kuznetsov, M.V. Piskunov, P.A. Strizhak, M.Yu. Chernetskii, Tech. Phys. Lett. 41, 810 (2015).

3. A.Yu. Varaksin, High Temp. 51, 377 (2013).

4. J.G. Leidenfrost, Int. J. Heat Mass Transf. 9, 1153 (1966).

5. G.V. Kuznetsov, M.V. Piskunov, P.A. Strizhak, Int. J. Heat Mass Transf. 92, 360 (2016). 